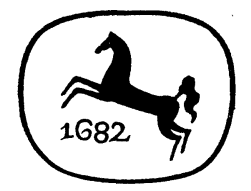

\title{
ZARTE EMPIRIE
}

Studien zur Literaturgeschichte 
Herman Meyer

\title{
Zarte Empirie
}

\author{
STUDIEN \\ ZUR \\ LITERATURGESCHICHTE
}

MCMLXIII

J. B. Metzlersche VerlagsbuchHandLung

STUTTGART 
Mit 7 Abbildungen

ISBN 978-3-476-99621-3

ISBN 978-3-476-99620-6 (eBook)

DOI 10.1007/978-3-476-99620-6

(C) Springer-Verlag GmbH Deutschland 1963

Ursprünglich erschienen bei J.B. Metzlersche Verlagsbuchhandlung und Carl Ernst Poeschel Verlag GmbH in Stuttgart 1963 
VOOR MIJN VRIEND

JAN ALER 
„ES GIBT EINE zarTe EMPIRIE, die sich mit dem Gegenstand innigst identisch macht und dadurch zur eigentlichen Theorie wird." Dieses Goethewort soll beileibe nicht dazu dienen, die hier vorgelegten Studien hinsichtlich ihrer Leistung anzupreisen. Ein solches Selbstlob würde die lächerlichste Hybris bedeuten. Nicht das Erreichte, sondern das Erstrebte ist gemeint. In diesem bescheideneren Sinne wage ich es, die kostbare Maxime anzuführen und ihr sogar den Titel dieses Buches zu entnehmen. Hier spricht sich genau der Leitgedanke aus, dem ich mich verpflichtet fühle und der die Richtung meines Strebens und Forschens in zunehmendem Maße bestimmt hat. Denn zwar sind es letztlich vielfach theoretische Einsichten, um die ich mich bemüht habe und bemühe; Anfang und Mitte des Weges aber, der zur Gewinnung solcher Einsichten führt, sind für mich nach wie vor die literarischen Gegebenheiten selbst in ihrer vollen Gegenständlichkeit. Andere mögen es anders halten; ich komme nicht aus ohne die ständige antäische Berührung mit dem festen Boden der Erfahrung, mit dem literarischen Gegenstand. Den Ausgangspunkt dieser Studien bildet zwar manchmal eine allgemeinere Überlegung, des öfteren aber auch ein auf den ersten Blick geringfügiges Detail tatsächlicher Art: irgendeine Einzelbeobachtung oder eine winzige philologische Entdeckung. Versenkt man sich mit Lust und Liebe und mit Andacht zum Kleinen in das charakteristische Spezielle, macht man sich mit ihm innigst vertraut (oder in Goethes kühnerer Formulierung: innigst identisch), so tritt es aus seiner mikrologischen Enge heraus, es stellt sich in weitere Bezüge hinein und enthüllt überraschend seine Relevanz auf allgemeinere, ja auf theoretische Ein- 
sichten hin. Auf diesem Wege, so hoffe ich, kann es gelingen und mag es auch mir hie und da gelungen sein, etwas zur Sichtung und Lösung spezifisch poetologischer Probleme beizutragen. Daß dies nicht der alleinseligmachende Weg zu gültiger Einsicht ist, versteht sich von selbst. Nicht weniger ist es mir aber gewiß, daß dieser Weg von der ehrwürdigen Tradition der philologischen Disziplin her legitimiert ist und $\mathrm{da} \beta$ er sich gerade in der gegenwärtigen Situation der Literaturwissenschaft und im Hinblick auf deren Zielsetzungen als gangbar und förderlich zu bewähren hat.

Die Probleme, die sich mir im Laufe der Jahre aufdrängten, sind vielheitlicher Art, wenn sie sich auch deutlich um einige Kernpunkte gruppieren. Sie betreffen vor allem die Struktur der Erzählkunst, die historische und ästhetische Eigenart von Vers und Strophe, das fesselnde Eigenleben literarischer Motive und die Beziehungen der Literatur zur bildenden Kunst. Die Auswahl dieser Aufsätze aus den letzten 15 Jahren ist so getroffen, daß die genannten Sachgebiete annähernd gleichmäßig zu ihrem Recht gelangen. Systematische Vollständigkeit wurde dabei nicht angestrebt; das Gemeinsame dieser Studien liegt mehr im Methodischen als in der Ausrichtung auf irgendwelche systematische Einheit, die höchstens als lockendes Ziel am fernen Horizont erscheint. Wie schon in meinem älteren Buch über den Typus der Sonderlinge in der deutschen Dichtung, und mit vielleicht etwas stärkerer Bewußtseinshelle in meiner jüngeren Arbeit über die ästhetische Bedeutung des Zitats im Roman, schwebt auch in diesen Aufsätzen durchgängig die methodische Frage vor, ob und wie sich das Individuelle und das Generelle der Literatur in gültiger Weise aufeinander beziehen lassen. Genauer gesagt: es handelt sich darum, die literarischen Einzelwerke in die übergreifenden Ordnungen literarhistorischer und allgemein-ästhetischer Art hineinzustellen, sie von diesen allgemeinen Aspekten her zu beleuchten und sie, paradoxerweise, gerade dadurch in ihrer einmaligen künstlerischen Eigenart besser zu verstehen. 


\section{INHALT}

Von der Freiheit des Erzählers S. 1

Zum Problem der epischen Integration S. 12

Raumgestaltung und Raumsymbolik in der Erzählkunst S. 33

Jean Pauls »Flegeljahre« S. 57

Vom Leben der Strophe in neuerer deutscher Lyrik S. 113

Goethes »Kleine Blumen, Kleine Blätter«S. 160

Der Bildungsphilister S. 179

Das Bild des Holländers in der deutschen Literatur S. 202

Kennst du das Haus? Zu Goethes Begegnung mit Palladio S.22S

Rilkes Cézanne-Erlebnis S. 244

Die Verwandlung des Sichtbaren

Die Bedeutung der modernen bildenden Kunst für

Rilkes späte Dichtung S. 287

Schillers philosophische Rhetorik S. 335

Anmerkungen S. 390, Register S. 412

Abbildungsnachweis S. 418 


\title{
Placet experiri
}

\author{
Petrarca - Hans Castorp
}

